\section{Tunguska event celebrated}

\section{London}

THE eightieth anniversary of the 'Tunguska event', the impact of a still-unidentified flying object in a remote region of eastern Siberia in summer 1980 has been marked by a scientific symposium at the Siberian Institute of Technology in Krasnnoyarsk and by the inauguration of yet another expedition to the epicentre of the explosion. Although the symposium produced no major breakthroughs on the nature of the 'object', it did evoke a consensus that the time had come to abandon the exotic theories of the 1970s

Ten years ago, acceptable hypotheses on the Tunguska object included a giant ball of ice and snow, antimatter, balllightning, a black hole, an alien spacecraft in distress and a nuclear explosion (possibly of extraterrestrial origin). This last suggestion came from one of the less conventional 'experts' - Aleksei Zolotov, originally an oil technologist co-opted by an academic expedition for his knowledge of the local terrain, who gradually emerged as an authority in his own right and who somehow never seems to encounter any problems in getting even his most bizarre theories published in Soviet journals. But even such an establishment figure as Professor Feliks Zigel of the Moscow Aviation Institute was prepared to argue, on the basis of the testimony of eye-witnesses, taken down long after the event, that the object had twice changed course in flight and hence was a spacecraft.

For the participants at this year's symposium, however, the time had come to abandon such fantasies. They called, instead, for a return to the fundamental data including a new survey of the site by both field expeditions and aerial photography teams. The last remnants of the debris from the explosion, they pointed out, are being swallowed up in the marshes, and there is no time to be lost. They urged that the proceedings of previous Tunguska symposia should be reprinted, and a catalogue of eyewitness testimonies drawn up.

The latest Tunguska expedition, which will work at the site for two months, will concentrate on a search for pulverized material which it is hoped can be identified as coming from the 'object'. (The absence of any meteorite-like body at the site has been a puzzle to investigators since the first expedition in 1927; hence the melting snowball and 'black hole' theories.) Further expeditions are planned for the next five years; laboratories in Moscow, Kiev and Novosibirsk will study the samples brought back, and the teams will report to the next Tunguska symposium in 1993

Vera Rich

\title{
Signs of a respite for the bruised Australian science enterprise
}

\section{Sydney}

THE 1988-89 Australian budget is being hailed as a triumph for the treasurer, Paul Keating. In his sixth budget, announced last week, he has turned a deficit of A $\$ 8,000$ million in $1983-84$ into a promised A $\$ 5,500$ million surplus. The hope is that with the budget back in balance, the worst will be over for science.

The treatment of the Commonwealth Scientific and Industrial Research Organization (CSIRO) is typical. With 7,200 employees, CSIRO is Australia's largest research body. This year it suffered its fifth successive year of cuts, losing $A \$ 13.6$ million from its $A \$ 347.8$ million budget of last year. But the government has promised that from now on the real value of support will be maintained and that future gains in outside revenue will not be taken away, giving CSIRO hope that there is light at the end of the tunnel.

Despite the cut, CSIRO's prospects should improve a little in the coming year. Completion of major capital works this year, such as the "Australia Telescope" radio telescope, will reduce the CSIRO's construction bill by $\mathrm{A} \$ 13.8$ million next year, so that money for research will be held virtually constant in dollar terms; in real terms a predicted inflation rate of 5.5 per cent means a reduction.

Outside revenues for CSIRO from royalties, contract research, and sales of real estate are expected to increase by A $\$ 27.8$ million to around $\mathbf{A} \$ 129$ million next year. This increase takes the total CSIRO budget to A $\$ 463.2$ million, up 6.5 per cent on last year and just keeping pace with inflation. The shift from government funding to industry funding necessarily entails a move from long-term basic research to short-term commmercially oriented work.

The government says it wants CSIRO to find 30 per cent of its funding from outside sources by 1991 . In the coming year the proportion should be 28 per cent. According to Keith Boardman, CSIRO's chief executive officer, the 30 per cent target might be exceeded. But he concedes that the morale of the organization, already very low, will suffer even more due to the inevitability of further staff reductions. Cuts over the last five years have resulted in a ratio of operating to salary expenditure which is unacceptably low.

In higher education, the budget gives effect to the reforms outlined by the Minister for Education, Employment, and Training, John Dawkins in a recent white paper (Nature 330, 592; 1987), including the unified national system and a graduate tax. Also in the budget was a plan to expand Australia's higher educa- tion system by 10 per cent by 1991 . The introduction of a graduate tax marks the end of free tertiary education in Australia. Under the "Higher Education Contribution Scheme" (HECS) each tertiary student will pay A $\$ 1,800$ for each year of their course. On average the annual charge will amount to $20 \%$ of actual course costs. Payment will be made as a levy of $1 \%, 2 \%$, or $3 \%$ on income tax, according income, until the money owing has been repayed. No money need be repaid until the student has a job with an annual salary of $\mathrm{A} \$ 22,000$ or more.

Research funds distibuted annually by the Australian Research Council (ARC) are to be increased in steps, from $\mathrm{A} \$ 78$ million in 1988 to $\mathrm{A} \$ 140$ million in 1991 .

Funding to the Australian Space Board is to be restored. The Space Board, established in 1986 with a budget of $A \$ 5.3$ million, had its funds slashed to $\mathrm{A} \$ 3.2$ million in 1987. In 1988-89 it will receive $\mathrm{A} \$ 5.4$ million

Charles Morgan

\section{Japan's mini-shuttle readied for flight}

Tokyo

JAPAN's Institute of Space and Astronautical Sciences plans to launch a space shuttle into the upper atmosphere later in the month from a balloon - but it is only a 2 -metre model.

The model, developed by a team at the institute led by Professor Makoto Nagatomo, has already been test-flown in the lower atmosphere by releasing it from a helicopter (see Nature 322, 201; 1986). But the flight, scheduled for 18 September, will be the first attempt at re-entry into the atmosphere.

The shuttle will lift off from the institute's space centre in Kyushu cradled in a gondola and will be carried to a height of 20 $\mathrm{km}$ by a balloon. A booster rocket will then blast the vehicle to a height of $83 \mathrm{~km}$ where the booster will separate and the shuttle will splash down in the Pacific Ocean several minutes later.

The institute's ultimate aim is to develop a Highly Manoeuvrable Experimental Space (HIMES) vehicle equipped with a cryogenic engine. It will be about seven times the size of the model. HIMES could then be used as an unmanned orbital re-entry vehicle for scientific experiments.

But the HIMES project has yet to get the official backing of the education ministry. And the model shuttle is supported only with 'preparatory' research funds of a few million dollars a year - hence the balloon, a cost-saving measure. David Swinbanks 